\title{
湖北星斗山地形变化对不同生活型植物叶功能性 状的影响
}

\section{王进 ${ }^{1}$ 朱 江 $^{1 *}$ 艾训儒 ${ }^{1}$ 姚 兰 ${ }^{1}$ 黄 小 ${ }^{1}$ 吴漫玲 ${ }^{1}$ 朱 $^{1}$ 洪建峰 $^{2}$}

${ }^{1}$ 湖北民族大学林学园艺学院, 湖北恩施 $445000 ;{ }^{2}$ 湖北星斗山国家级自然保护区管理局, 湖北恩施 445000

摘 要 探究地形变化对不同生活型植物叶功能性状的影响有助于深入理解森林群落物种组成的维持特征。该研究以湖北星 斗山常绿落叶阔叶混交林为研究对象, 测量了 50 个样地中 224 种木本植物的叶面积、叶厚度、叶干质量、叶干物质含量和比 叶面积, 运用单因素方差分析揭示了乔木、灌木和木质藤本的叶功能性状变异特征, 并采用偏曼特尔检验分别从群落水平和 物种水平分析了地形变化对不同生活型木本植物叶功能性状的影响。研究发现: 不同生活型植物叶性状变异系数分布范围为 23.42\%-110.45\%; 不同生活型之间的植物叶功能性状差异明显。群落水平上, 海拔与乔木叶干质量、灌木叶面积和木质藤本 叶厚度显著正相关, 坡度仅对灌木和木质藤本比叶面积具有显著影响, 坡向与灌木叶厚度、叶干质量和比叶面积显著正相关。 物种水平上, 海拔比坡度和坡向对植物叶功能性状影响更为显著, 且不同物种对地形变化的敏感度不一致; 在控制空间结构 影响后, 地形因子对植物叶功能性状的影响降低。该研究结果表明, 不同生活型植物的叶功能性状对地形变化的响应格局不 同, 这可能是星斗山常绿落叶阔叶混交林植物多样性的主要维持机制。

关键词 常绿落叶阔叶混交林; 性状变异; 空间结构; 偏曼特尔检验

王进, 朱江, 艾训儒, 姚兰, 黄小, 吴漫玲, 朱强, 洪建峰 (2019). 湖北星斗山地形变化对不同生活型植物叶功能性状的影响. 植物生态学报, 43, 447-457. DOI: $10.17521 /$ cjpe.2018.0228

\section{Effects of topography on leaf functional traits across plant life forms in Xingdou Mountain, Hubei, China}

WANG Jin ${ }^{1}$, ZHU Jiang ${ }^{1 *}$, AI Xun-Ru ${ }^{1}$, YAO Lan ${ }^{1}$, HUANG Xiao ${ }^{1}$, WU Man-Ling ${ }^{1}$, ZHU Qiang ${ }^{1}$, and HONG JianFeng $^{2}$

${ }^{1}$ School of Forestry and Horticulture, Hubei Minzu University, Enshi, Hubei 445000, China; and ${ }^{2}$ Bureau of Xingdoushan National Nature Reserve, Enshi, Hubei 445000, China

\section{Abstract}

Aims Exploring the effects of topography on leaf functional traits across plant life forms is helpful to understand species diversity maintenance in forests. The objective of this study is to test how leaf traits among trees, shrubs and woody lianas respond to topographic variability distinctly.

Methods Five leaf functional traits (leaf area, leaf thickness, leaf dry mass, leaf dry matter content and specific leaf area) were measured for 224 woody plant species with contrasting life forms (trees, shrubs and woody lianas) across 50 plots of evergreen and deciduous broadleaved mixed forests in Xingdou Mountain, Hubei Province, China. The variation in leaf functional traits of trees, shrubs and woody lianas were analyzed by one-way ANOVA. We tested the significance of the effect of topographic variability on leaf functional traits of woody plants by Partial Mantel test at community level and species level, respectively.

Important findings The coefficient of variation of leaf functional traits in different life forms ranged from $23.42 \%$ to $110.45 \%$, and there were significant differences in leaf functional traits among different life forms. At the community level, there was a significant positive correlation between altitude and tree leaf dry mass, shrub leaf area and woody liana leaf thickness. Slope only had significant influences on shrub and woody liana leaf area, and slope aspect had significant effects on shrubs leaf thickness. There was a significant positive correlation between leaf dry mass and specific leaf area. At the species level, the effects of slope and slope aspect on plant leaf functional traits were more significant than those of altitude, and the sensitivity in the responses of functional 
traits to topographic variation was not consistent across different species. After controlling for the effects of spatial structure, the effects of topographic factors on functional traits of plant leaves were reduced. The results showed that the responses of leaf functional traits to topographic variation were different in different life forms, which might be one of the major mechanisms maintaining plant diversity in the evergreen and deciduous broadleaved mixed forests of Xingdou Mountain.

Key words evergreen and deciduous broadleaved mixed forest; variation of traits; spatial structure; Partial Mantel test

Wang J, Zhu J, Ai XR, Yao L, Huang X, Wu ML, Zhu Q, Hong JF (2019). Effects of topography on leaf functional traits across plant life forms in Xingdou Mountain, Hubei, China. Chinese Journal of Plant Ecology, 43, 447-457. DOI: 10.17521/cjpe.2018.0228

植物功能性状是指能够响应环境变化, 并对生 态系统功能有一定影响的植物表型特征(Díaz \& Cabido, 2001; 孟婷婷等, 2007)。植物叶功能性状能 够反映植物适应环境变化而形成的适应对策, 指示 植物对环境变化的响应(Cornelissen et al., 2003b; Reich, 2003)。在植物各器官中, 由于叶片具有生长 周期短、更新快、数量多, 同时对生境条件变化最 敏感等特点, 叶功能性状成为表征植物资源利用、 能量分配以及生长对策权衡的重要指标(Kayama et al., 2002; Wang \& Chen, 2013), 被越来越多的研究 所使用(张林和罗天祥, 2004; 祝介东等, 2011; 黄海 侠等, 2013)。

植物功能性状在物种沿环境梯度的分布格局中 起重要作用。在不同尺度上, 地带性气候条件是决 定物种、生活型或植被类型分布的主要因素(宋永昌, 2001), 而在同一气候区, 地形是影响植被分布格局 的最重要的因子(Sakai \& Ohsawa, 1994; Hara et al., 1996; Dai et al., 2010)。地形通过地貌过程和形态变 化控制光、热、水和土壤养分等资源的空间再分配 (沈泽吴等, 2000)。其中, 海拔作为主要地形因子, 会显著影响温度、降水和光照等的梯度变化, 从而 决定热量和水分的分配, 使不同生活型植物叶功能 性状产生适应性变化(王常顺和汪诗平，2015)。坡 向、坡度等地形因子通过影响光照、地表径流等因 素间接影响水热条件(Cantón et al., 2004; 李钰等, 2013a), 导致植物叶性状在阴坡(北坡)与阳坡(南坡) 的差异(李钰等, 2013b)。Mark等(2010)的研究表明, 不同海拔高度以及南北两坡的植被生活型分布显著 不同。可见, 植物叶功能性状和地形因子之间关系 密切, 且不同地形因子对植物叶功能性状产生的影 响各异。

近年来, 关于地形因子对植物叶功能性状影响 的研究较多(丁佳等, 2011; 张奇平, 2011; 李钰等, 2013a，2013b; 党晶晶等, 2014; 陈晨等, 2015), 但
是, 从不同生活型角度研究植物叶功能性状与地形 变异关系的研究较少。事实上, 森林生态系统中植 物生活型的差异是植物在竞争和共存中形成生物多 样性的主要形式(Harrod et al., 1999; Aem et al., 2003; Waltz et al., 2003; Homyack et al., 2004)。不同 生活型植物叶性状本身的差异, 导致其对光照、降 水、温度、养分等资源的需求与利用存在差异(李家 湘等, 2017), 并在不同地形条件下会产生不同的变 异(Westoby \& Wright, 2006; 钟巧连等, 2018), 所以 研究不同生活型植物叶功能性状与地形因子之间的 关系对于揭示生物多样性维持机制和群落构建机制 尤为重要。

湖北星斗山国家级自然保护区属于亚热带区域, 地形起伏较大, 其典型植被类型为常绿落叶阔叶混 交林, 是常绿阔叶林向落叶阔叶林过渡的一种特殊 的森林类型(中国森林编辑委员会, 2000)。该类型森 林中植物种类丰富、区系复杂, 且对环境变化敏感 (黄永涛等, 2015), 为研究地形变化对不同生活型植 物性状的影响提供了良好的研究对象。目前, 对常 绿落叶阔叶混交林不同生活型植物叶功能性状与地 形变异之间关系的研究较少。本文以星斗山亚热带 常绿落叶阔叶混交林中的木本植物为研究对象, 分 析地形变化对不同生活型植物叶功能性状的影响, 为森林群落构建机制和生物多样性维持机制的研究 提供参考。

\section{1 材料和方法}

\section{1 研究区域概况}

研究区域位于鄂西南的星斗山自然保护区(地 理坐标为 $29.95^{\circ}-30.17^{\circ} \mathrm{N}, 108.95^{\circ}-109.45^{\circ} \mathrm{E}$ ), 保 护区总面积68 $339 \mathrm{hm}^{2}$, 海拔范围815.0-1 $751.2 \mathrm{~m}$ 。 该区域处于北亚热带与暖温带的过渡地带, 属 亚热带季风气候, 年日照时间 $1298.9 \mathrm{~h}$, 年平均气 温 $12{ }^{\circ} \mathrm{C}$, 无霜期 255 天，年降水量 $1471.7 \mathrm{~mm}$, 其 
中 5-9 月的降水量约占全年的 $71 \%$, 年蒸发量 $1109.2 \mathrm{~mm}$ 。

\section{2 样地设置与调查}

2013年7-8月, 在湖北星斗山国家级自然保护 区的亚热带常绿落叶阔叶混交林内, 参照CTFS (Center of Tropical Forest Sciences)样地调查技术规 范(Condit, 1998), 在不同海拔、坡度和坡向下, 建立 50 个规格为 $20 \mathrm{~m} \times 20 \mathrm{~m}$ 大小的森林动态监测样地, 并记录每个样地所在海拔、坡度、坡向等环境因子。 样地基本情况如图1所示。

在各样地中利用网格法将其划分成 16 个 $5 \mathrm{~m} \times$ $5 \mathrm{~m}$ 的样块, 对其中所有胸径在 $1.0 \mathrm{~cm}$ 以上的木本植 物(乔木、灌木和木质藤本)进行调查, 调查指标包括 物种名称、树高、胸径、生长状况和相对坐标等, 共 调查到 224 种植物, 其中乔木 147 种, 灌木 58 种, 木 质藤本 19 种。

\section{3 叶片采集}

2014年 6-8月, 参照植物功能性状采样方法 (Pérezharguindeguy et al., 2013), 分别对样地内调查 到的 224 种木本植物(乔木 147 种, 灌木 58 种, 木质藤 本19种)进行叶片采集。对每个样地内胸径在 $10 \mathrm{~cm}$ 以上的个体(包括木质藤本)全部采样, 对样地内胸 径小于 $10 \mathrm{~cm}$ 的个体按照胸径从大到小依次选择前 5 个个体进行采样, 如果样地中物种的个体数不足 5 个则全部进行采样。利用枝剪统一在植株林冠的向 阳面采集5-10枚(复叶采集4-5组)长势良好、无病虫 害的完整叶片。将采集的叶片样本用自封袋密封后 装入保鲜箱中, 迅速带回实验室进行叶功能性状的 测定。

在 50 个样地中, 采集到的乔木物种数为 $7-30$ 种, 灌木物种数为 $2-14$ 种, 木质藤本物种数为 $1-4$ 种(图 2 )。

\section{4 叶功能性状测定}

在各样地采集的叶片样本中, 每个个体选取2 枚最为完整、大小相近的健康叶片, 用叶面积仪 (LI-COR 3000C Area Meter, LI-COR, Lincoln, USA) 测定每个叶片(包括叶柄)的叶面积 $\left(L A, \mathrm{~cm}^{2}\right)$; 使用 数显千分尺进行叶片厚度 $(L T, \mathrm{~mm})$ 的测定, 测定时 避开叶片主脉，选择叶片的中心部位进行测量; 使 用精度为 $0.001 \mathrm{~g}$ 的电子天平测定叶鲜质量 $(L F M, \mathrm{~g})$; 把测量完的叶片装入原信封, 放入 $80{ }^{\circ} \mathrm{C}$ 烘箱中烘 干至恒质量, 测叶干质量 $(L D M, \mathrm{~g})$ 。

叶干物质含量 $\left(L D M C, \mathrm{~g} \cdot \mathrm{g}^{-1}\right)$ 、比叶面积 $(S L A$, $\mathrm{cm}^{2} \cdot \mathrm{g}^{-1}$ ) 按照下列公式(Cornelissen et al., 2003a; Pérezharguindeguy et al., 2013)进行计算:

$$
\begin{aligned}
& L D M C=\frac{L D M}{L F M} \times 100 \% \\
& S L A=\frac{L A}{L D M} \times 100 \%
\end{aligned}
$$

\section{5 数据处理及分析方法}

\subsection{1 地形数据}

海拔以实际观测记录值表示; 坡度依据样地 4 个角的高程计算, 每个样地每次取 3 个角的高程确 定一个平面作为 1 次计算, 4 次计算的均值作为一个 样地坡度, 并进行弧度化处理; 坡向以正东为起点， 采用罗盘仪记录顺时针旋转的角度值作为样地坡向 数据, 并将角度值进行正弦化处理。

\subsection{2 物种数据}

群落水平: 以样地为单元, 建立不同生活型植 物的叶功能性状矩阵, 作为群落水平的分析对象。

物种水平: 分别对乔木(147种), 灌木(58种), 木质藤本(19种)的重要值进行计算, 选择重要值前2 的物种，共计 6 个优势种作为物种水平的分析对
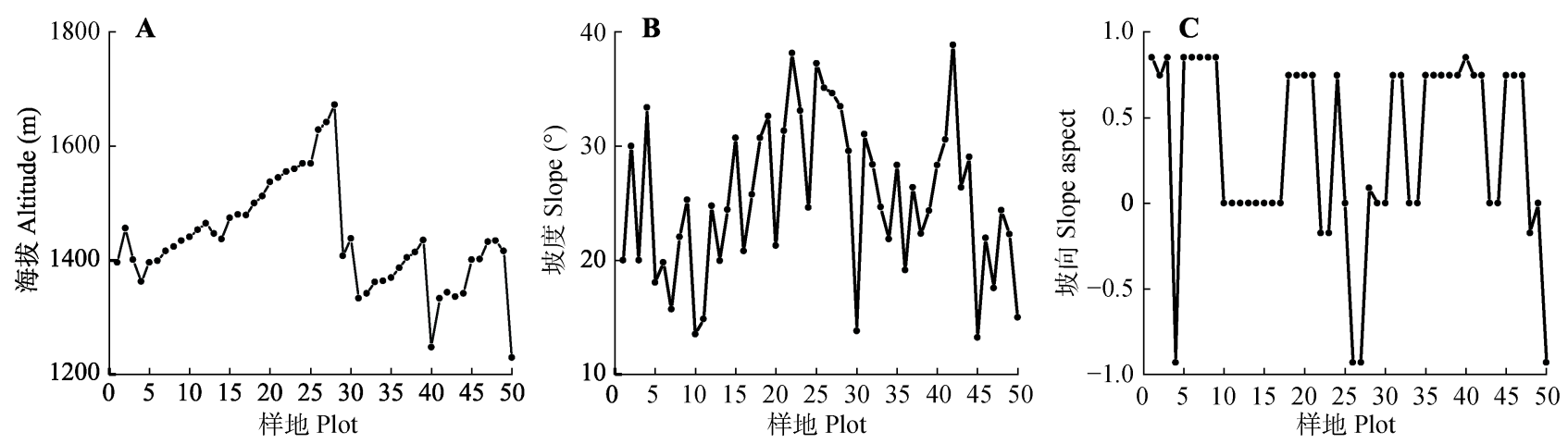

图1 星斗山50个样地地形基本情况。海拔和坡度为实际观测值, 坡向为正弦化数据。

Fig. 1 Basic topography status of 50 plots in Xingdou Moutain. The altitude and slope were presented as the actual observation data, and the aspects were sinusoidally transformed. 


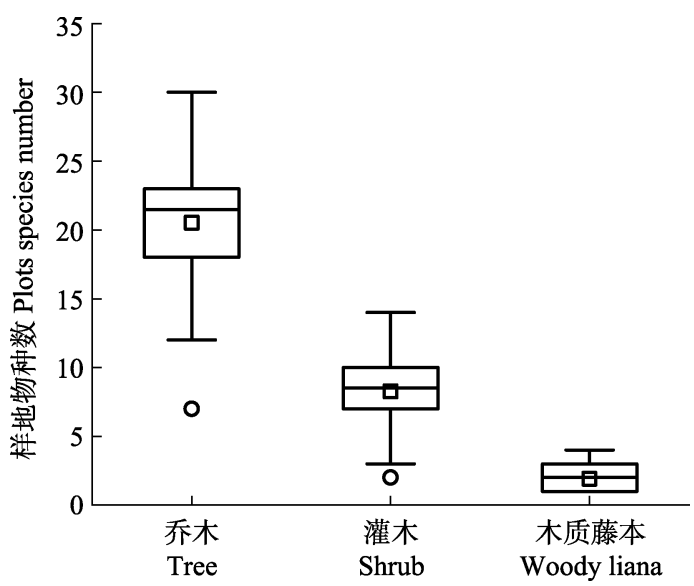

图2 星斗山50个样地不同生活型植物的物种多样性。箱体 中“口”为平均值、“一”为中位数; “ $O$ ”为异常值。

Fig. 2 Species diversity of plants from different life forms in 50 plots of Xingdou Mountain. In the box, “ $\square$ " is the average, "-" is the median. " $\bigcirc$ " is the abnormal value.

象。其中, 乔木优势种为川陕鹅耳枥(Carpinus fargesiana)、齿缘吊钟花(Enkianthus serrulatus)，灌木 优势种为翅柃(Eurya alata)、红果树(Stranvaesia davidiana), 木质藤本优势种为大金刚藤(Dalbergia dyeriana)、中华猕猴桃(Actinidia chinensis)。

\subsection{3 分析方法}

(1)叶功能性状变异分析。分别从群落和物种水 平分析了不同生活型植物叶功能性状的变异。其中, 在群落水平, 利用变异系数 $(C V)$ 衡量叶功能性状间 的变异程度, 利用单因素方差分析以及最小显著差 异(LSD)后置检验法检验不同生活型间的叶功能性 状变异; 在物种水平, 利用 $C V$ 衡量 6 个优势种叶功 能性状间的变异程度。

(2)偏曼特尔分析。运用该方法可以排除空间结 构的多重作用及其与地形因子之间的交互作用，从 而明确地形因子对不同生活型植物叶功能性状的独 立影响。基于各样地叶功能性状均值数据建立“叶功 能性状矩阵”; 基于各样地海拔、坡度和坡向数据建 立“地形因子矩阵”; 将各样地经纬度坐标转化为百 分制数据并建立“空间距离矩阵”，运用 R软件“ncf” 包中的“Partial Mantel test”函数分析群落水平下地 形变化对不同生活型植物叶功能性状的影响(999次 置换); 采用同样的方法, 以 6 个优势种为对象, 分 析物种水平下地形变化对植物叶功能性状的影响 (999次置换)。

数据的计算与统计分析通过Excel 2016、SPSS 22.0和R 3.5.1等软件平台完成, 并通过Origin 2018
软件完成制图。

\section{2 结果和分析}

\section{1 不同生活型叶功能性状变异特征}

群落水平不同生活型植物叶功能性状及其变异 特征如图3所示。对于 5 种叶功能性状平均值, 木质 藤本的 $L A\left(92.93 \mathrm{~cm}^{2}\right) 、 L T(0.24 \mathrm{~mm})$ 和 $L D M(0.42 \mathrm{~g})$ 最大, 而 $L D M C$ 是乔木 $\left(0.34 \mathrm{~g} \cdot \mathrm{g}^{-1}\right)$ 最大, $S L A$ 是灌木 $\left(298.19 \mathrm{~cm}^{2} \cdot \mathrm{g}^{-1}\right)$ 最大。 $L A 、 L T$ 和 $L D M$ 的变异系数均 表现为乔木 $>$ 灌木 $>$ 木质藤本, 而 $L D M C$ 和 $S L A$ 表现 为木质藤本 $>$ 乔木 $>$ 灌木。

方差分析及 $L S D$ 检验结果表明，3种生活型两两 之间的 $L A 、 L D M$ 和 $L D M C$ 皆差异极显著 $(p<0.001)$ 。 $L T$ 在乔木和木质藤本间差异极显著 $(p<0.001)$, 在 灌木和木质藤本间差异显著 $(p<0.05)$, 而乔木和灌 木之间差异不显著 $(p>0.05)$ 。SLA在乔木和灌木、 灌木和木质藤本间差异极显著 $(p<0.001)$, 而乔木 和木质藤本间差异不显著 $(p>0.05)$ 。

物种水平优势种植物叶功能性状变异特征如图 4所示。5种叶功能性状平均值显示, 中华猕猴桃的 $L A\left(107.44 \mathrm{~cm}^{2}\right) 、 L T(0.35 \mathrm{~mm})$ 和 $L D M(0.55 \mathrm{~g})$ 最大, 而 $L D M C$ 是川陕鹅耳枥 $\left(0.39 \mathrm{~g} \cdot \mathrm{g}^{-1}\right)$ 最大, $S L A$ 是红果 树 $\left(376.99 \mathrm{~cm}^{2} \cdot \mathrm{g}^{-1}\right)$ 最大。根据变异系数来看, 大金刚 藤的 $L A$ 和 $L T$ 变异最大, 而 $L D M 、 L D M C$ 和 $S L A$ 是波 叶红果树变异最大。

\section{2 地形变化对植物叶功能性状的影响}

地形对不同生活型植物叶功能性状在群落水 平和物种水平上的影响如表 1 和表 2 所示。在控制空 间结构(样地地理距离)影响下，地形因子对不同生 活型植物的叶功能性状的显著影响均有所降低。

群落水平上(表1), 在控制空间结构影响后, 仅 乔木类植物的 $L D M$ 、灌木类植物的 $L A$ 和木质藤本类 植物的 $L T$ 与海拔呈显著正相关关系 $(p<0.05)$, 而灌 木和木质藤本 2 类植物的 SLA均受到坡度的显著影 响 $(p<0.05)$, 仅灌木类植物的 $L T 、 L D M$ 和SLA受到 坡向的显著影响 $(p<0.05)$; 除此之外, 3 种地形因子 对其他叶功能性状的影响并未达到显著水平 $(p>$ $0.05)$ 。

物种水平上(表2), 在控制空间结构影响后, 3 种 地形因子中海拔相比坡度和坡向对6种优势种植物 叶功能性状的影响更为显著，除齿缘吊钟花外， 

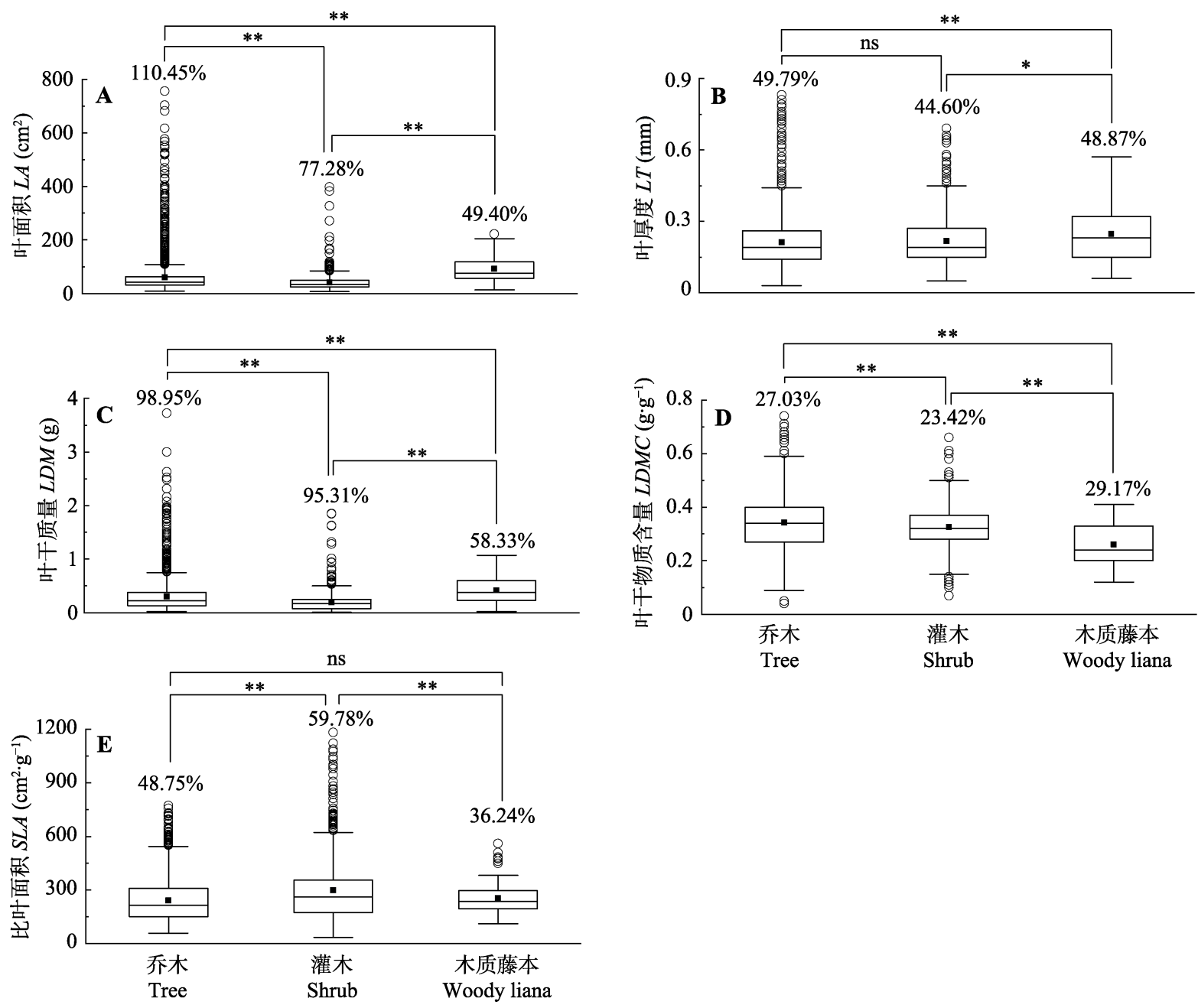

图3 群落水平 3 种生活型植物叶功能性状变异。图中百分数据为变异系数 $(C V)$; 箱体中“口”为平均值、“一”为中位数; “ $O$ ”为 异常值。**, $p<0.01 ; *, p<0.05 ; \mathrm{ns}, p>0.05$ 。

Fig. 3 Variation of leaf functional traits across three life forms of plants at community level. The figures on top of the boxed are the coefficients of variation $(\mathrm{CV})$ of that trait across all plots. In the box, "曰" is the average, "—" is the median. "O" is the abnormal value. $L A$, leaf area; $L T$, leaf thickness; $L D M$, leaf dry mass; $L D M C$, leaf dry matter content; $S L A$, specific leaf area. **, $p<0.01 ; *$, $p<0.05 ; \mathrm{ns}, p>0.05$.

其他 5 种优势种植物的 $L A$ 均与海拔呈显著正相关关 系 $(p<0.05)$, 而坡度和坡向对6种优势植物的 5 种叶 功能性状的影响并未表现出明显的一致性; 另外, 不同地形因子对同一物种叶功能性状的影响不同, 中华狝猴桃的 $L A$ 和 $S L A$ 均与海拔呈显著正相关关系 $(p<0.05)$, 却与坡度呈显著负相关关系 $(p<0.05)$, 而大金刚藤的 $L A$ 与海拔和坡向呈显著正相关关系 $(p<0.05)$ ，而与坡度呈显著负相关关系 $(p<0.05)$ ； 不同物种叶功能性状对于地形变异的敏感度并不一 致，齿缘吊钟花仅 $L D M C$ 与海拔具有显著负相关关 系 $(p<0.05)$, 其他性状与 3 种地形因子均无显著相 关性 $(p>0.05)$, 而波叶红果树和大金刚藤的叶功能 性状对地形变异更为敏感。

\section{3 讨论}

\section{1 不同生活型叶功能性状的变异}

生活型是植物对综合生境长期适应后在其生 理、结构以及外部形态上表现的一种具有一定稳定 性的特征反映(高贤明和陈灵芝, 1998)。不同生活型 物种的分布特点与水分、光照等多种非生物环境因 子相关(Toledo et al., 2011)。本研究发现, 除了木质 藤本与乔木间的 $S L A$ 和灌木与乔木间的 $L T$ 差异不显 著外, 其他性状在不同生活型间均有显著差异, 这 说明在同一环境中, 不同生活型的植物采取不同的 叶性状来适应环境(周丽等, 2014)。本研究中灌木的 LDMC低于乔木，而其SLA大于乔木和木质藤本。 

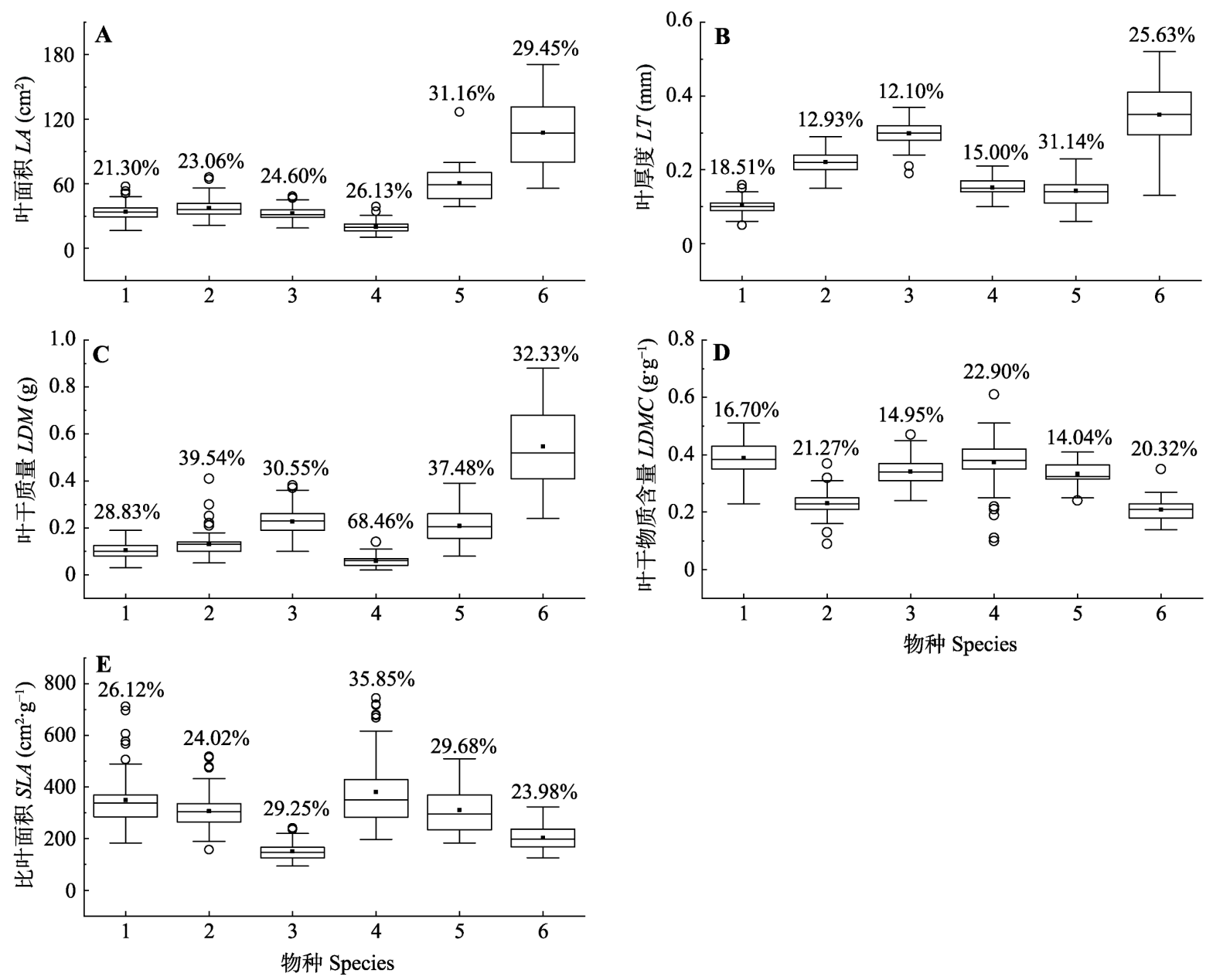

图4 优势种植物叶功能性状变异(物种水平)。图中百分数据为变异系数 $(C V)$; 箱体中“回”为平均值、“一”为中位数; “ $O$ ”为异 常值。横坐标1-6代表物种: 1, 川陕鹅耳枥; 2, 齿缘吊钟花; 3, 翅柃; 4, 红果树; 5, 大金刚藤; 6, 中华猕猴桃。

Fig. 4 Variation in leaf functional traits across dominant species (species level). $L A$, leaf area; $L T$, leaf thickness; $L D M$, leaf dry mass; $L D M C$, leaf dry matter content; $S L A$, specific leaf area. The figures on top of the boxes are the coefficients of variation of each trait for a species across all sampled plots. In the box, " $\square$ " is the average, "—" is the median. "O" is the abnormal value. 1-6 represent species in the abscissa: 1, Carpinus fargesiana; 2, Enkianthus serrulatus; 3, Eurya alata; 4, Stranvaesia davidiana; 5, Dalbergia dyeriana; 6, Actinidia chinensis.

乔木具有较高的 $L D M C$ 可能是为了避免损失更多的 水分(Kenzo et al., 2015; He \& Yan, 2018), 而SLA较 小能降低植物内部水分的丧失(Poorter et al., 2008), 提高水分的利用效率。灌木的植株生物量相对乔木 较小, 对养分和水分的需求量较少。因此乔木的 $L D M C$ 高于灌木，而 $S L A$ 低于灌木。

乔木和灌木是亚热带常绿落叶阔叶混交林的主 体部分, 它们的分布变化受人为干扰、地形或者土 壤环境状况等多种因子组合共同影响(吴征捡, 1980; 宋永昌, 2004)。除了乔木、灌木以外, 木质藤本对 亚热带常绿落叶阔叶混交林的结构和生产力有非常 重要的作用。较高的SLA反映资源较为丰富, 而较低 的SLA反映资源较为贫㾑(Cornelissen et al., 2003b)。 在本研究中, 木质藤本的SLA相较于乔木、灌木偏低,
而 $L A$ 均值高于乔木、灌木, 体现木质藤本采取不断 累积叶面积, 提高光截获能力的保守策略, 这也是 木质藤本能在林隙特殊生境成功生存和定居的重要 原因。

\section{2 不同生活型植物叶功能性状对地形变化的响} 应特征

在植物叶功能性状与地形因子相关性的研究 中, 可能因研究对象和区域的差异, 地形因子对植 物叶功能性状的影响并不完全一致(孟婷婷等, 2007; 丁佳等, 2011; 李宏伟等, 2012)。在多种地形因子中, 海拔是影响植物叶功能性状的主要因子(丁佳等, 2011; 刘玉平等, 2017)。随着海拔的升高，降水量减 少, 气温和气压降低, 太阳辐射增强, 植物减少, 气 温和气压降低, 太阳辐射增强, 植物生长季变短, 
进而改变植物叶功能性状(Cornwell et al., 2006; Cornwell \& Ackerly, 2009; 刘晓娟和马克平, 2015)。 本研究中, 在群落和物种水平, 海拔皆是影响植物 叶功能性状的主要因子, 这一结果与其他学者的研 究结果一致。

在群落水平上, 控制空间影响后, 坡度对灌木 和木质藤本的SLA均产生显著影响, 而坡向仅对灌 木的 $L T 、 L D M$ 和 $S L A$ 具有显著影响(表1)。坡度会直 接影响土壤水分及养分(方精云等, 2004), 且植物的 SLA对土壤养分变化比较敏感, 灌木和木质藤本多 生存于林下和林隙, 相比乔木而言对土壤养分有着更 高的依赖度(Putz, 1984; Schnitzer \& Bongers, 2002)。 坡向主要影响光照条件, 相比处于林下的灌木, 森林 中乔木和木质藤本多分布于林分上层空间, 光照条 件较好, 由此导致灌木的部分叶功能性状对于坡向 的变化更为敏感。可见, 由于植物生活型的不同, 获 取水分、光照等资源的方式不同, 导致其叶功能性 状对于某一地形因子的变化具有不同的敏感度。

在本文的研究结果中(表1, 表2), 相较于未控 制空间结构影响, 在控制空间结构影响后, 地形因
子对植物叶功能性状的独立影响总体上有所降低, 但也存在部分与之相反的情况。当以小尺度样地为 研究单元时, 由于样地的空间分布和地形的差异, 在一定程度上会导致样地内植物能利用的光照、水 分和土壤养分等资源存在差异(宋永昌, 2001; 丁佳 等, 2011), 而植物的叶功能性状会根据资源分配的 差异产生不同的适应策略(沈泽昊, 2002; Cornwell et al., 2006)。所以, 在分析植物叶功能性状与环境 之间的关系问题时, 应考虑空间结构与地形因子之 间的交互作用。

综上所述，星斗山常绿落叶阔叶混交林不同生 活型植物叶功能性状均呈现出较高的变异系数, 且 不同生活型之间植物叶功能性状差异明显, 这与森 林群落结构复杂, 生物多样性高具有直接关系。3 种 地形因子中, 海拔相比坡度和坡向对植物叶功能性 状具有更显著的影响; 不同生活型植物的叶功能性 状对单一地形因子具有不同的敏感性; 地形和空间 结构会共同导致多种环境因子的改变, 在以小尺度 为研究单元分析地形因子对植物叶功能性状的影响 时，取样点的空间结构也不应被忽视。

表1 群落水平上不同生活型植物叶功能性状与地形因子的偏曼特尔检验

Table 1 Partial Mantel tests for the relationships between leaf functional traits of different life forms and topographic factors at community level

\begin{tabular}{|c|c|c|c|c|c|c|c|c|}
\hline \multirow[t]{2}{*}{$\begin{array}{l}\text { 生活型 } \\
\text { Life form }\end{array}$} & \multirow[t]{2}{*}{$\begin{array}{l}\text { 性状 } \\
\text { Trait }\end{array}$} & \multirow{2}{*}{$\begin{array}{c}\text { 空间结构 } \\
\text { Spatial } \\
\text { structure }\end{array}$} & \multicolumn{3}{|c|}{$\begin{array}{c}\text { 未控制空间结构影响 } \\
\text { Uncontrolled spatial structure effect }\end{array}$} & \multicolumn{3}{|c|}{$\begin{array}{c}\text { 控制空间结构影响 } \\
\text { Controlling the influence of spatial structure }\end{array}$} \\
\hline & & & $\begin{array}{c}\text { 海拔 } \\
\text { Altitude }\end{array}$ & $\begin{array}{l}\text { 坡度 } \\
\text { Slope }\end{array}$ & $\begin{array}{c}\text { 坡向 } \\
\text { Slope aspect }\end{array}$ & $\begin{array}{c}\text { 海拔 } \\
\text { Altitude }\end{array}$ & $\begin{array}{l}\text { 坡度 } \\
\text { Slope }\end{array}$ & $\begin{array}{c}\text { 坡向 } \\
\text { Slope aspect }\end{array}$ \\
\hline \multirow{5}{*}{$\begin{array}{l}\text { 乔木 } \\
\text { Tree }\end{array}$} & $L A\left(\mathrm{~cm}^{2}\right)$ & $0.26^{*}$ & $0.27^{*}$ & 0.07 & $0.15^{*}$ & 0.10 & 0.00 & 0.09 \\
\hline & $L T(\mathrm{~mm})$ & -0.02 & -0.02 & -0.02 & 0.00 & -0.01 & -0.02 & 0.01 \\
\hline & $L D M(\mathrm{~g})$ & 0.15 & $0.20^{*}$ & 0.02 & 0.12 & $0.15^{*}$ & -0.02 & 0.09 \\
\hline & $\operatorname{LDMC}\left(\mathrm{g} \cdot \mathrm{g}^{-1}\right)$ & $0.13^{*}$ & 0.08 & -0.00 & 0.05 & -0.09 & -0.04 & 0.02 \\
\hline & $S L A\left(\mathrm{~cm}^{2} \cdot \mathrm{g}^{-1}\right)$ & 0.06 & 0.07 & 0.01 & 0.09 & 0.04 & -0.01 & 0.08 \\
\hline \multirow{5}{*}{$\begin{array}{l}\text { 灌木 } \\
\text { Shrub }\end{array}$} & $L A\left(\mathrm{~cm}^{2}\right)$ & $0.18^{*}$ & $0.23^{* *}$ & 0.05 & $0.13^{*}$ & $0.15^{*}$ & -0.00 & 0.09 \\
\hline & $L T(\mathrm{~mm})$ & $0.39^{* *}$ & $0.36^{* *}$ & 0.02 & $0.19^{* *}$ & 0.03 & -0.09 & $0.11^{*}$ \\
\hline & $\operatorname{LDM}(\mathrm{g})$ & $0.32^{* *}$ & $0.31^{* *}$ & $0.19^{*}$ & $0.34^{* *}$ & 0.07 & 0.12 & $0.29^{* *}$ \\
\hline & $\operatorname{LDMC}\left(\mathrm{g} \cdot \mathrm{g}^{-1}\right)$ & 0.15 & 0.11 & 0.12 & 0.02 & -0.04 & 0.08 & -0.01 \\
\hline & $S L A\left(\mathrm{~cm}^{2} \cdot \mathrm{g}^{-1}\right)$ & $0.30^{* *}$ & $0.31^{* *}$ & $0.23^{* *}$ & $0.19^{* *}$ & 0.10 & $0.16^{*}$ & $0.13^{*}$ \\
\hline \multirow{5}{*}{$\begin{array}{l}\text { 木质藤本 } \\
\text { Woody liana }\end{array}$} & $L A\left(\mathrm{~cm}^{2}\right)$ & -0.02 & -0.03 & -0.07 & 0.01 & -0.02 & -0.07 & 0.02 \\
\hline & $L T(\mathrm{~mm})$ & 0.23 & $0.39^{*}$ & 0.21 & 0.11 & $0.40^{* *}$ & 0.14 & 0.05 \\
\hline & $\operatorname{LDM}(\mathrm{g})$ & -0.15 & $-0.16^{*}$ & -0.04 & -0.05 & -0.05 & 0.01 & -0.02 \\
\hline & $\operatorname{LDMC}\left(\mathrm{g} \cdot \mathrm{g}^{-1}\right)$ & -0.07 & -0.08 & 0.04 & -0.09 & -0.05 & 0.06 & -0.07 \\
\hline & $S L A\left(\mathrm{~cm}^{2} \cdot \mathrm{g}^{-1}\right)$ & 0.16 & 0.20 & -0.06 & 0.02 & 0.12 & $-0.12^{*}$ & -0.02 \\
\hline
\end{tabular}

$L A$, 叶面积; $L T$, 叶厚度; $L D M$, 叶干质量; $L D M C$, 叶干物质含量; $S L A$, 比叶面积。根据控制不同因子和叶功能性状之间进行 999 次置换得出Partial Mantel系数及其显著性。**, $p<0.01 ; *, p<0.05$ 。

$L A$, leaf area; $L T$, leaf thickness; $L D M$, leaf dry mass; $L D M C$, leaf dry matter content; SLA, specific leaf area. The Partial Mantel coefficients and their significance were obtained by 999 times of randomization. ${ }^{* *}, p<0.01 ; *, p<0.05$. 
表2 物种水平上不同生活型植物叶功能性状与地形因子的偏曼特尔检验

Table 2 Partial Mantel tests for the relationships between leaf functional traits of different life forms and topographic factors at species level across

\begin{tabular}{|c|c|c|c|c|c|c|c|c|}
\hline \multirow[t]{2}{*}{$\begin{array}{l}\text { 物种 } \\
\text { Species }\end{array}$} & \multirow[t]{2}{*}{$\begin{array}{l}\text { 性状 } \\
\text { Trait }\end{array}$} & \multirow{2}{*}{$\begin{array}{c}\text { 空间结构 } \\
\text { Spatial } \\
\text { structure }\end{array}$} & \multicolumn{3}{|c|}{$\begin{array}{c}\text { 未控制空间结构影响 } \\
\text { Uncontrolled spatial structure effect }\end{array}$} & \multicolumn{3}{|c|}{$\begin{array}{c}\text { 控制空间结构影响 } \\
\text { Controlling the influence of spatial structure }\end{array}$} \\
\hline & & & $\begin{array}{c}\text { 海拔 } \\
\text { Altitude }\end{array}$ & $\begin{array}{l}\text { 坡度 } \\
\text { Slope }\end{array}$ & $\begin{array}{c}\text { 坡向 } \\
\text { Slope aspect }\end{array}$ & $\begin{array}{c}\text { 海拔 } \\
\text { Altitude }\end{array}$ & $\begin{array}{l}\text { 坡度 } \\
\text { Slope }\end{array}$ & $\begin{array}{c}\text { 坡向 } \\
\text { Slope aspect }\end{array}$ \\
\hline \multirow{5}{*}{$\begin{array}{l}\text { 川陕鹅耳杤 } \\
\text { Carpinus fargesi- } \\
\text { ana }\end{array}$} & $L A\left(\mathrm{~cm}^{2}\right)$ & $0.27^{*}$ & $0.34^{*}$ & 0.16 & 0.20 & $0.24^{*}$ & 0.07 & 0.12 \\
\hline & $L T(\mathrm{~mm})$ & $0.40^{* *}$ & $0.43^{* *}$ & 0.09 & $0.29^{* *}$ & 0.15 & -0.07 & $0.20^{*}$ \\
\hline & $\operatorname{LDM}(\mathrm{g})$ & $0.37^{* *}$ & $0.38^{* *}$ & $0.19^{*}$ & $0.16^{*}$ & 0.12 & 0.06 & 0.07 \\
\hline & $\operatorname{LDMC}\left(\mathrm{g} \cdot \mathrm{g}^{-1}\right)$ & $0.21^{*}$ & 0.12 & -0.05 & $0.17^{*}$ & -0.16 & $-0.14^{*}$ & 0.11 \\
\hline & $S L A\left(\mathrm{~cm}^{2} \cdot \mathrm{g}^{-1}\right)$ & $0.35^{*}$ & $0.38^{*}$ & $0.21^{*}$ & 0.15 & 0.16 & 0.09 & 0.06 \\
\hline \multirow{5}{*}{$\begin{array}{l}\text { 齿缘吊钟花 } \\
\text { Enkianthus } \\
\text { serrulatus }\end{array}$} & $L A\left(\mathrm{~cm}^{2}\right)$ & $0.18^{*}$ & $0.17^{*}$ & -0.01 & -0.03 & 0.03 & -0.02 & -0.09 \\
\hline & $L T(\mathrm{~mm})$ & -0.10 & -0.10 & 0.04 & -0.06 & -0.03 & 0.04 & -0.03 \\
\hline & $\operatorname{LDM}(\mathrm{g})$ & $0.29^{*}$ & $0.30^{*}$ & 0.03 & 0.05 & 0.11 & 0.02 & -0.04 \\
\hline & $\operatorname{LDMC}\left(\mathrm{g} \cdot \mathrm{g}^{-1}\right)$ & 0.17 & 0.06 & 0.02 & 0.04 & $-0.17^{*}$ & 0.02 & -0.01 \\
\hline & $S L A\left(\mathrm{~cm}^{2} \cdot \mathrm{g}^{-1}\right)$ & 0.06 & 0.08 & -0.01 & -0.06 & 0.07 & -0.01 & -0.08 \\
\hline 翅柃 & $L A\left(\mathrm{~cm}^{2}\right)$ & $0.38^{* *}$ & $0.40^{* *}$ & 0.12 & 0.04 & $0.17^{*}$ & 0.02 & -0.06 \\
\hline \multirow[t]{4}{*}{ Eurya alata } & $L T(\mathrm{~mm})$ & 0.02 & 0.05 & -0.02 & 0.07 & 0.08 & -0.03 & 0.07 \\
\hline & $\operatorname{LDM}(\mathrm{g})$ & $0.15^{*}$ & $0.18^{*}$ & 0.01 & 0.07 & 0.12 & -0.03 & 0.04 \\
\hline & $\operatorname{LDMC}\left(\mathrm{g} \cdot \mathrm{g}^{-1}\right)$ & $0.22^{* *}$ & $0.20^{*}$ & -0.02 & 0.02 & 0.01 & -0.08 & -0.04 \\
\hline & $S L A\left(\mathrm{~cm}^{2} \cdot \mathrm{g}^{-1}\right)$ & 0.11 & 0.07 & 0.02 & $0.20^{* *}$ & -0.07 & -0.01 & $0.18^{* *}$ \\
\hline \multirow{5}{*}{$\begin{array}{l}\text { 红果树 } \\
\text { Stranvaesia } \\
\text { davidiana }\end{array}$} & $L A\left(\mathrm{~cm}^{2}\right)$ & 0.15 & $0.24^{*}$ & $0.16^{*}$ & 0.03 & $0.21^{*}$ & 0.13 & -0.02 \\
\hline & $L T(\mathrm{~mm})$ & -0.03 & -0.08 & -0.05 & 0.05 & -0.10 & -0.04 & 0.07 \\
\hline & $\operatorname{LDM}(\mathrm{g})$ & $0.30^{*}$ & $0.37^{*}$ & 0.00 & $0.39^{* *}$ & $0.23^{*}$ & -0.08 & $0.32^{* *}$ \\
\hline & $\operatorname{LDMC}\left(\mathrm{g} \cdot \mathrm{g}^{-1}\right)$ & 0.09 & 0.16 & 0.03 & 0.11 & 0.15 & 0.01 & 0.09 \\
\hline & $S L A\left(\mathrm{~cm}^{2} \cdot \mathrm{g}^{-1}\right)$ & $0.29^{*}$ & $0.36^{*}$ & 0.02 & $0.32^{* *}$ & $0.23^{*}$ & -0.05 & $0.25^{* *}$ \\
\hline \multirow{5}{*}{$\begin{array}{l}\text { 大金刚藤 } \\
\text { Dalbergia } \\
\text { dyeriana }\end{array}$} & $L A\left(\mathrm{~cm}^{2}\right)$ & 0.21 & $0.38^{* *}$ & -0.14 & $0.62^{* *}$ & $0.33^{*}$ & $-0.14^{*}$ & $0.60^{*}$ \\
\hline & $L T(\mathrm{~mm})$ & $0.37^{*}$ & 0.07 & -0.14 & 0.05 & -0.13 & -0.15 & -0.12 \\
\hline & $\operatorname{LDM}(\mathrm{g})$ & -0.05 & 0.00 & -0.08 & -0.13 & 0.03 & -0.08 & -0.12 \\
\hline & $L D M C\left(\mathrm{~g} \cdot \mathrm{g}^{-1}\right)$ & 0.27 & -0.15 & -0.05 & -0.09 & $-0.32^{* *}$ & -0.05 & $-0.23^{*}$ \\
\hline & $S L A\left(\mathrm{~cm}^{2} \cdot \mathrm{g}^{-1}\right)$ & 0.01 & $0.27^{*}$ & 0.01 & 0.12 & $0.29^{*}$ & 0.01 & 0.12 \\
\hline \multirow{5}{*}{$\begin{array}{l}\text { 中华猕猴桃 } \\
\text { Actinidia } \\
\text { chinensis }\end{array}$} & $L A\left(\mathrm{~cm}^{2}\right)$ & $0.43^{* *}$ & $0.50^{* *}$ & 0.06 & -0.01 & $0.29^{*}$ & $-0.25^{* *}$ & -0.10 \\
\hline & $L T(\mathrm{~mm})$ & -0.08 & -0.08 & -0.07 & 0.01 & -0.02 & -0.03 & 0.02 \\
\hline & $\operatorname{LDM}(\mathrm{g})$ & 0.21 & 0.11 & 0.07 & -0.01 & -0.17 & -0.06 & -0.05 \\
\hline & $\operatorname{LDMC}\left(\mathrm{g} \cdot \mathrm{g}^{-1}\right)$ & $-0.20^{*}$ & $-0.17^{*}$ & $-0.17^{* *}$ & -0.16 & 0.03 & -0.07 & -0.13 \\
\hline & $S L A\left(\mathrm{~cm}^{2} \cdot \mathrm{g}^{-1}\right)$ & 0.12 & $0.28^{*}$ & -0.12 & 0.11 & $0.40^{* *}$ & $-0.23^{* *}$ & 0.09 \\
\hline
\end{tabular}

$L A$, 叶面积; $L T$, 叶厚度; $L D M$, 叶干质量; $L D M C$, 叶干物质含量; SLA, 比叶面积。根据控制不同因子和叶功能性状之间进行 999 次置换得出Partia Mantel系数及其显著性。**, $p<0.01 ; *, p<0.05$ 。

$L A$, leaf area; $L T$, leaf thickness; $L D M$, leaf dry mass; $L D M C$, leaf dry matter content; SLA, specific leaf area. The Partial Mantel coefficients and their significance were obtained by 999 times of randomization. **, $p<0.01 ; *, p<0.05$.

致谢 感谢生物资源保护与利用湖北省重点实验室 开放基金(PKLHB1714)和湖北民族学院博士启动基 金(MY2018B027)资助; 感谢中国林业科学研究院 冯广博士对本研究提供的帮助。

\section{参考文献}

Aem W, Fule PZ, Covington WW, Moore MM (2003). Diversity in ponderosa pine forest structure following ecological restoration treatments. Forest Science, 49, 885-900.

Cantón Y, Barrio GD, Solé-Benet A, Lázaro R (2004). Topog- raphic controls on the spatial distribution of ground cover in the Tabernas badlands of SE Spain. Catena, 55, 341-365.

Chen C, Liu DH, Wu JJ, Kang MY, Zhang JT, Liu QR, Liang $\mathrm{Y}$ (2015). Leaf traits of Quercus wutaishanica and their relationship with topographic factors in Mount Dongling. Chinese Journal of Ecology, 34, 2131-2139. [陈晨, 刘丹 辉, 吴键军, 康慕谊, 张金屯, 刘全儒, 梁钰 (2015). 东 灵山地区辽东栎叶性状与地形因子关系. 生态学杂志, 34, 2131-2139.]

Condit R (1998). Tropical Forest Census Plots: Methods and www.plant-ecology.com 
Results from Barro Colorado Island, Panama and A Comparison with Other Plots. Springer-Verlag, Berlin Heidelberg, New York.

Cornelissen JHC, Cerabolini B, Castrodíez P, Villarsalvador P, Montserratmartí G, Puyravaud JP, Maestro M, Werger MJA, Aerts R (2003a). Functional traits of woody plants: Correspondence of species rankings between field adults and laboratory-grown seedlings? Journal of Vegetation Science, 14, 311-322.

Cornelissen JHC, Lavorel S, Garnier E, Buchmann N, Gurvich DE, Reich PB, Steege HT, Morgan HD, Heijden MGAV (2003b). A handbook of protocols for standardised and easy measurement of plant functional traits worldwide. Australian Journal of Botany, 51, 335-380.

Cornwell WK, Ackerly DD (2009). Community assembly and shifts in plant trait distributions across an environmental gradient in coastal California. Ecological Monographs, 79, 109-126.

Cornwell WK, Schwilk LDW, Ackerly DD (2006). A traitbased test for habitat filtering: Convex hull volume. Ecology, 87, 1465-1471.

Dai N, Hirabuki Y, Mochida Y (2010). Influence of microlandforms on forest structure, tree death and recruitment in a Japanese temperate mixed forest. Ecological Research, 18, 533-547.

Dang JJ, Zhao CZ, Li Y, Hou ZJ, Dong XG (2014). Variations with slope in stem and leaf traits of Melica przewalskyi in alpine grassland. Chinese Journal of Plant Ecology, 38, 1307-1314. [党晶晶, 赵成章, 李钰, 侯兆疆, 董小刚 (2014). 高寒草地甘肃臭草茎-叶性状的坡度差异性. 植 物生态学报, 38, 1307-1314.]

Díaz S, Cabido M (2001). Vive la difference: Plant functional diversity matters to ecosystem processes. Trends in Ecology \& Evolution, 16, 646-655.

Ding J, Wu Q, Yan H, Zhang SR (2011). Effects of topographic variations and soil characteristics on plant functional traits in a subtropical ever green broad-leaved forest. Biodiversity Science, 19，158-167. [丁佳, 吴茜, 问慧, 张守仁 (2011). 地形和土壤特性对亚热带常绿阔叶林内植物功 能性状的影响. 生物多样性, 19, 158-167.]

Editorial Board of Forest in China (2000). Forest in China. Vol. 3, Broad-leaved Forest. China Forestry Publishing House, Beijing. [中国森林编辑委员会 (2000). 中国森林第三 卷: 阔叶森林. 中国林业出版社, 北京.]

Fang JY, Shen ZH, Cui HT (2004). Ecological characteristics of mountains and research issues of mountain ecology. Biodiversity Science, 12，10-19. [方精云, 沈泽昊, 崔海 亭 (2004). 试论山地的生态特征及山地生态学的研究 内容. 生物多样性, 12, 10-19.]

Gao XM, Chen LZ (1998). The revision of plant life form system and an analysis of the life-form spectrum of forest plants in the warm temperate zone of China. Acta Botanica
Sinica, 40, 553-559. [高贤明, 陈灵芝 (1998). 植物生活 型分类系统的修订及中国暖温带森林植物生活型谱分 析. 植物学报, 40, 553-559.]

Hara M, Hirata K, Fujihara M, Oono K (1996). Vegetation structure in relation to micro-landform in an evergreen broad-leaved forest on Amami Ohshima Island, south-west Japan. Ecological Research, 11, 325-337.

Harrod RJ, Mcrae BH, Hartl WE (1999). Historical stand reconstruction in ponderosa pine forests to guide silvicultural prescriptions. Forest Ecology and Management, 114, 433-446.

He D, Yan ER (2018). Size-dependent variations in individual traits and trait scaling relationships within a shade-tolerant evergreen tree species. American Journal of Botany, 105, $1165-1174$.

Homyack JA, Harrison DJ, Krohn WB (2004). Structural differences between precommercially thinned and unthinned conifer stands. Forest Ecology and Management, 194, 131-143.

Huang HX, Yang XD, Sun BW, Zhang ZH, Yan ER (2013). Variability and association of leaf traits between currentyear and former-year leaves in evergreen trees in Tiantong, Zhejiang, China. Chinese Journal of Plant Ecology, 37, 912-921. [黄海侠, 杨晓东, 孙宝伟, 张志浩, 阎恩荣 (2013). 浙江天童常绿植物当年生与往年生叶片性状的 变异与关联. 植物生态学报, 37, 912-921.]

Huang YT, Yao L, Ai XR, Lü SA, Ding Y (2015). Quantitative classification of the subtropical evergreen-deciduous broadleaved mixed forest and the deciduous and evergreen species composition structure across two national nature reserves in the southwest of Hubei, China. Chinese Journal of Plant Ecology, 39, 990-1002. [黄永涛, 姚兰, 艾训 儒, 吕世安, 丁易 (2015). 鄂西南两个自然保护区亚热 带常绿落叶阔叶混交林类型及其常绿和落叶物种组成 结构分析. 植物生态学报, 39, 990-1002.]

Kayama M, Sasa K, Koike T (2002). Needle life span, photosynthetic rate and nutrient concentration of Picea glehnii, $P$. jezoensis and $P$. abies planted on serpentine soil in northern Japan. Tree Physiology, 22, 707-716.

Kenzo T, Inoue Y, Yoshimura M, Yamashita M, Tanakaoda A, Ichie T (2015). Height-related changes in leaf photosynthetic traits in diverse Bornean tropical rain forest trees. Oecologia, 177, 191-202.

Li HW, Wang XA, Guo H (2012). Leaf functional traits of different forest communities in Ziwuling Mountains of Loess Plateau. Chinese Journal of Ecology, 31, 544-550. [李宏伟, 王孝安, 郭华 (2012). 黄土高原子午岭不同 森林群落叶功能性状. 生态学杂志, 31, 544-550.]

Li JX, Xu WT, Xiong GM, Wang Y, Zhao CM, Lu ZJ, Li YL, Xie ZQ (2017). Leaf nitrogen and phosphorus concentration and the empirical regulations in dominant woody plants of shrublands across southern China. Chinese Journal 
of Plant Ecology, 41, 31-42. [李家湘, 徐文婷, 熊高明, 王杨, 赵常明, 卢志军, 李跃林, 谢宗强 (2017). 中国 南方灌从优势木本植物叶的氮、磷含量及其影响因素. 植物生态学报, 41, 31-42.]

Li Y, Zhao CZ, Dong XG, Hou ZJ, Ma XL, Zhang Q (2013a). Twig and leaf trait differences in Stellera chamaejasme with slope in alpine grassland. Chinese Journal of Plant Ecology, 37, 709-717. [李钰, 赵成章, 董小刚, 侯兆疆, 马小丽, 张茜 (2013a). 高寒草地狼毒枝-叶性状的坡度 差异性. 植物生态学报, 37, 709-717.]

Li Y, Zhao CZ, Dong XG, Hou ZJ, Ma XL, Zhang Q (2013b). Responses of Stellera chamaejasme twig and leaf traits to slope aspect in alpine grassland of Northwest China. Chinese Journal of Ecology, 32, 3145-3151. [李钰, 赵成章, 董小刚, 侯兆疆, 马小丽, 张茜 (2013b). 高寒草地狼毒 枝-叶性状对坡向的响应. 生态学杂志, 32, 3145-3151.]

Liu XJ, Ma KP (2015). Plant functional traits-concepts, applications and future directions. Science China: Life Science, 45, 325-339. [刘晓娟, 马克平 (2015). 植物功能性状研 究进展. 中国科学: 生命科学, 45, 325-339.]

Liu YP, Liu GF, Baiyila DF, Cheng WY, Chen ZJ, Jiang LL (2017). Effects of topographic factors on leaf traits of dominant species in different forest communities in Daqinggou Nature Reserves. Scientia Silvae Sinicae, 53(3)，154-162. [刘玉平, 刘贵峰, 达福白乙拉, 程伟燕, 陈志婧, 姜丽丽 (2017). 地形因子对大青沟自然保护区 不同森林群落叶性状的影响。林业科学, 53(3), 154-162.]

Mark AF, Dickinson KJM, Allen J, Smith R, West CJ (2010). Vegetation patterns, plant distribution and life forms across the alpine zone in southern Tierra del Fuego, Argentina. Austral Ecology, 26, 423-440.

Meng TT, Ni J, Wang GH (2007). Plant functional traits, environments and ecosystem functioning. Journal of Plant Ecology (Chinese Version), 31, 150-165. [孟婷婷, 倪健, 王国宏 (2007). 植物功能性状与环境和生态系统功能. 植物生态学报, 31, 150-165.]

Pérezharguindeguy N, Díaz S, Garnier E, Lavorel S, Poorter H, Jaureguiberry P, Bretharte MS, Cornwell WK, Craine JM, Gurvich DE, Urcelay C, Veneklaas EJ, Reich PB, Poorter L, Wright IJ, Ray P, Enrico L, Pausas JG, Vos AC, Buchmann N, Funes G, Quétier F, Hodgson JG, Thompson K, Morgan HD, Steege H, Heijden MGA, Sack L, Blonder B, Poschlod P, Vaieretti MV, Conti G, Staver AC, Aquino S, Cornelissen JHC (2013). New handbook for standardised measurement of plant functional traits worldwide. Australian Journal of Botany, 61, 167-234.

Poorter L, Wright SJ, Paz H, Ackerly DD, Condit R, Ibarramanríquez G, Harms KE, Licona JC, Martínez-ramos M, Mazer SJ (2008). Are functional traits good predictors of demographic rates? Evidence from five neotropical forests. Ecology, 89, 1908-1920.
Putz FE (1984). How trees avoid and shed liana. Biotropica, 1, $19-23$.

Reich PB (2003). The evolution of plant functional variation: Traits, spectra, and strategies. International Journal of Plant Sciences, 164, S143-S164.

Sakai A, Ohsawa M (1994). Topographical pattern of the forest vegetation on a river basin in a warm-temperate hilly region, central Japan. Ecological Research, 9, 269-280.

Schnitzer SA, Bongers F (2002). The ecology of lianas and their role in forests. Trends in Ecology \& Evolution, 5, 223-230.

Shen ZH (2002). A multi-scale study on the vegetationenvironment relationship of a mountain forest transect. Acta Ecologica Sinica, 22, 461-470. [沈泽昊 (2002). 山 地森林样带植被-环境关系的多尺度研究. 生态学报, 22, 461-470.]

Shen ZH, Zhang XS, Jin YX (2000). Gradient analysis of the influence of mountain topography on vegetation pattern. Acta Phytoecologica Sinica, 24, 430-435. [沈泽昊, 张新 时, 金义兴 (2000). 地形对亚热带山地景观尺度植被格 局影响的梯度分析. 植物生态学报, 24, 430-435.]

Song YC (2001). Vegetation Ecology. East China Normal University Press, Shanghai. [宋永昌 (2001). 植被生态学. 华东师范大学出版社, 上海.]

Song YC (2004). Tentative classification scheme of evergreen broad-leaved forests of China. Acta Phytoecologica Sinica, 28，435-448. [宋永昌 (2004). 中国常绿阔叶林分类试 行方案. 植物生态学报, 28, 435-448.]

Toledo M, Poorter L, Claros MP, Alarcón A, Balcázar J, Leaño C, Licona JC, Llanque O, Vroomans V, Zuidema P, Bongers $F$ (2011). Climate is a stronger driver of tree and forest growth rates than soil and disturbance. Journal of Ecology, 99, 254-264.

Waltz AEM, Fulé PZ, Covington WW, Moore MM (2003). Diversity in ponderosa pine forest structure following ecological restoration treatments. Forest Science, 49, 885-900.

Wang CS, Wang SP (2015). A review of research on responses of leaf traits to climate change. Chinese Journal of Plant Ecology, 39, 206-216. [王常顺, 汪诗平 (2015). 植物叶 片性状对气候变化的响应研究进展. 植物生态学报, 39, 206-216.]

Wang HY, Chen H (2013). Plant functional groups based on vegetative and reproductive traits in a subtropical forest community. Journal of Forest Research, 18, 482-490.

Westoby M, Wright IJ (2006). Land-plant ecology on the basis of functional traits. Trends in Ecology \& Evolution, 21, 261-268.

Wu ZY (1980). Chinese Vegetation. Science Press, Beijing. 279-306. [吴征镒 (1980). 中国植被. 科学出版社, 北 京. 279-306.]

Zhang L, Luo TX (2004). Advances in ecological studies on

www.plant-ecology.com 
leaf lifespan and associated leaf traits. Acta Ecologica Sinica, 28, 844-852. [张林, 罗天祥 (2004). 植物叶寿命 及其相关叶性状的生态学研究进展. 植物生态学报, 28 , 844-852.]

Zhang QP (2011). Differentiation Patterns of Leaf Traits of Main Trees Along Altitudinal and Micro-Topographical Gradients on Tianmushan Mountain. Master degree dissertation, East China Normal University, Shanghai. [张奇 平 (2011). 天目山主要树种叶性状在海拔梯度和微地 形上的分异格局. 硕士学位论文, 华东师范大学, 上 海.]

Zhong QL, Liu LB, Xu X, Yang Y, Guo YM, Xu HY, Cai XL, Ni J (2018). Variations of plant functional traits and adaptive strategy of woody species in a karst forest of central Guizhou Province, southwestern China. Chinese Journal of Plant Ecology, 42, 562-572. [钟巧连, 刘立斌, 许金金, 杨勇, 郭银明, 许海洋, 蔡先立, 倪健 (2018). 黔中喀 斯特木本植物功能性状变异及其适应策略. 植物生态
学报, 42, 562-572.]

Zhou L, Zhang WQ, Tang HH, Chen WG, Pan LJ (2014). Ecological stoichiometry characteristics of young-and-middle aged conifer-broadleaved plantation in Southern Subtropical Region. Ecology and Environmental Sciences, 23, 1732-1738. [周丽, 张卫强, 唐洪辉, 陈伟光, 盘李军 (2014). 南亚热带中幼龄针阔混交林生态化学计量特征. 生态环境学报, 23, 1732-1738.]

Zhu JD, Meng TT, Ni J, Su HX, Xie ZQ, Zhang SR, Zheng YR, Xiao CW (2011). Within-leaf allometric relationships of mature forests in different bioclimatic zones vary with plant functional types. Chinese Journal of Plant Ecology, 35, 687-698. [祝介东, 孟婷婷, 倪健, 苏宏新, 谢宗强, 张守仁, 郑元润, 肖春旺 (2011). 不同气候带间成熟林 植物叶性状间异速生长关系随功能型的变异. 植物生 态学报, 35, 687-698.]

责任编委: 阎恩荣 责任编辑: 李 敏 实习编辑: 赵 航 